www.jmscr.igmpublication.org Impact Factor 5.84

Index Copernicus Value: 83.27 ISSN (e)-2347-176x ISSN (p) 2455-0450 crossref DOI: https://dx.doi.org/10.18535/jmscr/v5i6.74

\title{
Spina Bifida in a Newborn - A Case Report
}

\section{Authors \\ Henry Robert M Lamare', Sunilbala K ${ }^{2}$ Y Tomba Singh $^{3}$, Ebormi Lytan ${ }^{4}$, Lalrammuana ${ }^{4}$}

${ }^{1}$ Post Graduate Trainee $3^{\text {rd }}$ Year, Department of Pediatrics, Regional Institute of Medical Sciences, Imphal

${ }^{2}$ Associate Professor, Department of Pediatrics, Regional Institute of Medical Sciences, Imphal

${ }^{3}$ Professor, Department of Pediatrics, Regional Institute of Medical Sciences, Imphal

${ }^{4}$ Post Graduate Trainee $2^{\text {nd }}$ Year, Department of Pediatrics, Regional Institute of Medical Sciences, Imphal

\begin{abstract}
Spina bifida is a neural tube defect with average incidence of 1-2 cases per 1000 population with female to male ratio of 1.2:1.These defects occur as a result to a teratogenic process that causes failed closure and abnormal differentiation of the embryonic neural tube. The major neural tube defects include spina bifida occulta, meningocele, myelomeningocele, encephalocele, anencephaly, dermal sinus. We report a case of a one-day-old female neonate who was delivered at term gestation and presented with respiratory distress and congenital anomaly. Local and systemic examination was thoroughly done and a clinical diagnosis of myelomeningocele, a severe form of spina bifida was made.
\end{abstract}

\section{Introduction}

Spina bifida is a treatable spinal cord malformation that occurs in varying degrees of severity. Classified as a defect of the neural tube and have a range of presentations, from stillbirth to incidental radiogra-phic findings of spina bifida occulta to a severe form, myelomeningocele which is visible at birth and presents with a spectrum of impairments, but the primary functional deficits are lower limb paralysis and sensory loss, bladder and bowel dysfunction and cognitive dysfunction. ${ }^{1}$ The anatomic level of the myelomeningocele sac roughly correlates with the patient's neurologic, motor and sensory deficits. ${ }^{2}$ It is associated with abnormal development of the cranial neural tube, which results inseveral characteristic CNS anomalies.
The Chiari type II malformation is characterized by cerebellar hypoplasia and varying degrees of caudal displacement of the lower brainstem into the upper cervical canal through the foramen magnum. This deformity impedes the flow and absorption of cerebrospinal fluid (CSF) and causes hydrocephalus, which occurs in more than $90 \%$ of infants with myelomeningocele. ${ }^{3}$ The etiology in most cases is multifactorial, involving genetic, racial and envir-onmental factors, in which nutrition, particularly folic acid intake, is key. Laboratory screening tests for neural tube defects can be performed through blood tests (maternal serum triple or quadruple screen), amniocentesis or both. These typically are used in combination with fetal ultrasonography. Prenatal diagnosis and ultrasonographic confirma-tion 
allow for preparation and parental referral to appropriate care services. The fetal presence of an open neural tube defect is marked by an elevated alpha-fetoprotein (AFP) level in the amniotic fluid. Peak concentrations of AFP in the 13th to 15th weeks of pregnancy permit diagnosis and ultrasonographic confirmation with amniocentesis generally is possible at $15-18$ weeks. In children with spina bifida, additional testing would include levels of anticonvulsants, urine cultures and perhaps cystometrograms and skin testing for latex sensitivity and enzyme-linked immunosorbent assay (ELISA) or skin prick. After birth, spinabifida can be clinically diagnosed and X-ray, an MRI, or a CT scan can be carried out to see if the defect is mild or severe. We report a case of myelomeningocele, a severe type of spina bifida which is diagnosed clinically after birth.

\section{Case Report}

A 1-day-old term female neonate weighing 2.59 $\mathrm{kg}$ delivered to a primi mother with pre-eclampsia by breech delivery, presented to us with complaints of respiratory distress and lesion at the back. The neonate was immediately admitted in the NICU for respiratory distress and congenital anomaly. Prior Ultrasound reports in the $3^{\text {rd }}$ semester showed dilated ventricles suggestive of ventriculopathy and anomaly scanat 26 weeks 2 days gestation showing features of dilated ventricles with hydrocephalus and increased peak systolic of umbilical artery. Abdominal examination revealed single umbilical artery and single umbilical vein and a lesion at lumbar region sized $15 \mathrm{~cm} * 12.5 \mathrm{~cm}$ containing a thin sac encasing fluid and spinal cord. Bruises present on both buttocks. Flaccid paralysis of the lower extremities was noted and deep reflexes were not elicited. Other systemic examinations were within normal limits.

Routine blood examinations were done including random blood sugar and sepsis screening. Sepsis screening was negative while RBS was $73 \mathrm{mg} / \mathrm{dL}$. Other hematological parameters were within normal limits.
The patient was referred to neurosurgeon and was advised ultrasound abdomen and MRI spine but these were not done because the patient was taken to another hospital for further treatment. The following figure showing a neonate with a congenital anomaly at lumbar region suggestive of myelomeningocele, a severe form of spina bifida (Figure 1).

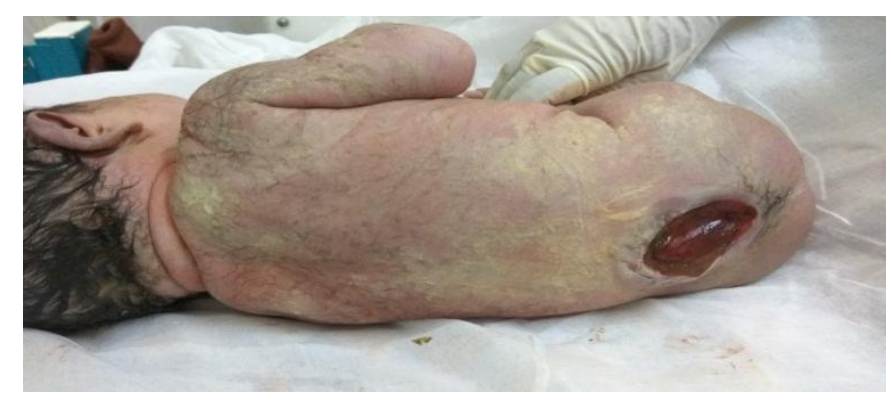

Figure 1: A neonate showing defective lesion at lumbar region suggestive of myelomeningocele.

\section{Discussion}

Neural tube defects (NTDs) account for the largest proportion of congenital anomalies of the CNS and result from failure of the neural tube to close and cause of NTDs remains unknown. The major NTDs include spina bifida occulta, meningocele, myelomeningocele, encephalocele, anencephaly, dermal sinus. ${ }^{4}$ Spina bifida is a neural tube defect with average prevalence of 0.9-1 cases per 1000 population with female to male ratio of 1.2:1. ${ }^{5}$ Myelomeningocele represents the most severe form of dysraphism, a so-called aperta or open form, involving the vertebral column and spinal cord, which occurs with an incidence of approximately $1 / 4,000$ live births. ${ }^{6}$

The cause is unknown, but the risk of recurrence after one affected child is $3-4 \%$ and increases to $10 \%$ with 2 prior affected children. Folate is intricately involved in the prevention and etiology of NTDs. Research in the 1980s showed correction of folic acid deficiency as an effective means of primary and recurrent prevention. ${ }^{7}$

The U.S. Public Health Service has recommended that all women of childbearing age and who are capable of becoming pregnant take $0.4 \mathrm{mg}$ of folic acid daily. If, however, a pregnancy is planned in 
high-risk women, supplementation should be started with $4 \mathrm{mg}$ of folic acid daily one month before pregnancy. ${ }^{6}$

Examination of the infant shows a flaccid paralysis of the lower extremities, an absence of deep tendon reflexes, a lack of response to touch and pain, and a high incidence of lower extremity deformities. Infants with myelomeningocele typically have an increasing neurologic deficit as it extends higher into the thoracic region. These infants sometimes have an associated kyphoticgibbus that requires neonatal orthopedic correction. Patients with a myelomeningocele in the upper thoracic or cervical region usually have a very minimal neurologic deficit and, in most cases, do not have hydrocephalus. They can have neurogenic bladder and bowel. Hydrocephalus in association with a type II Chiari malformation develops in at least $80 \%$ of patients with myelomeningocele. Generally, the lower the deformity is in the neuraxis (sacrum), the less likely is the risk of hydrocephalus. Ventricular enlargement may be indolent and slow growing or may be rapid causing a bulging anterior fontanel, dilated scalp veins, setting-sun appearance of the eyes, irritability, and vomiting associated with an increased head circumference. About 15\% of infants with hydrocephalus and Chiari II malformation develop symptoms of hindbrain dysfunction, including difficulty feeding, choking, stridor, apnea, vocal cord paralysis, pooling of secretions and spasticity of the upper extremities, which, if untreated, can lead to death.

Management and supervision of a child with a myelomeningocele require a multidisciplinary team approach, including surgeons, physicians, and therapists, with one individual (often a pediatrician) acting as the advocate and coordinator of the treatment program.

Careful evaluation and reassessment of the genitourinary system are some of the most important components of the management. Teaching the parents and ultimately the patient to regularly catheterize a neurogenic bladder is a crucial step in maintaining a low residual volume and bladder pressure that prevents urinary tract infections and reflux leading to pyelonephritis, hydronephrosisand bladder damage. Periodic urine cultures and assessment of renal function, including serum electrolytes and creatinine as well as renal scans, vesiculourethrograms (VCUGs), renal ultrasonography and cystometrograms(CMGs), are obtained according to the risk status and progress of the patient and the results of the physical examination. This approach to urinary tract management has greatly reduced the need for urologic diversionary procedures and significantly decreased the morbidity and mortality associated with progressive renal disease in these patients. Some children can become continent with surgical implantation of an artificial urinary sphincter or bladder augmentation at a later age. ${ }^{6}$

In utero surgical closure of a spinal lesion has been successful in a few centers. This suggests that the defects may be progressive in utero and that prenatal closure might prevent the development of further loss of function. In utero diagnosis is facilitated by maternal serum alphafetoprotein screening and by fetal ultrasonography. The mortality rate is $10-15 \%$, and most deaths occur before age $4 \mathrm{yr}$ and at least $70 \%$ of survivors have normal intelligence, but learning problems and seizure disorders are more common than in the general population. ${ }^{6}$ Mortality rates reported for untreated infants range from 90$100 \%$ based on several studies in recent years. An infant aged 2 months with untreated myelomeningocele has only a $28 \%$ likelihood of living 7 years. ${ }^{8}$ Previous episodes of meningitis or ventriculitis adversely affect intellectual and cognitive function. Renal dysfunction is one of the most important determinants of mortality.

\section{References}

1. Vinck A, Nijhuis-van der Sanden MW, Roeleveld NJ, et al. Motor profile and cognitive functioning in children with spina bifida. Eur J Paediatr Neurol. 2010 Jan. 14(1):86-92. 
2. Fletcher JM, Copeland K, Frederick JA, et al. Spinal lesion level in spina bifida: a source of neural and cognitive heterogeneity. J Neurosurg. 2005 Apr. 102(3):268-79.

3. Mitchell LE, Adzick NS, Melchionne J, et al. Spina bifida. Lancet 2004; 364:1885-95.

4. Kinsman SL, Johnston MV. Neural tube defects. In: Kliegman RM, Stanton BF, St Geme III JW, Schor NF, editors. Nelson Textbook of Pediatrics. First South Asia Edition. Gurgaon (Haryana), India: Reed Elsevier India Private Limited; 2015.p. 2802.

5. Milunsky A, Jick H, Jick SS, Bruell CL, MacLaughlin DS, Rothman KJ, et al. Multivitamin/folic acid supplementation in early pregnancy reduces the prevalence of neural tube defects. JAMA. 1989 Nov 24. 262(20):2847-52.

6. Kinsman SL, Johnston MV. Myelomeningocele . In: Kliegman RM, Stanton BF, St Geme III JW, Schor NF, editors. Nelson Textbook of Pediatrics. First South Asia Edition. Gurgaon (Haryana), India: Reed Elsevier India Private Limited; 2015.p.2805-6.

7. Centers for Disease Control and Prevention. Spina bifida and anencephaly before and after folic acid mandate-United States, 1995-1996 and 19992000. MMWR Morb Mortal Wkly Rep. 2004 May 7. 53(17):362-5.

8. da Silva SA, de Almeida MF, Moron AF, Cavalheiro S, Dastoli PA, Guinsburg R. Resuscitation at birth in neonates with meningomyelocele. J Perinat Med. 2014 Jan. 42(1):113-9. 